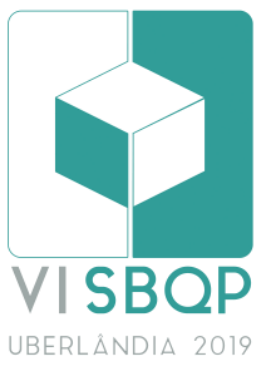

\title{
A QUALIDADE DO ESPAÇO CONSTRUÍDO E A PERCEPÇÃO EM PARQUES LINEARES
}

\author{
GODOY, Larissa Riza Carvalho \\ UFU (Universidade Federal de Uberlândia), e-mail: larissa.godoy@ufu.br
}

\begin{abstract}
RESUMO
Diante de um cenário indagado por questões visuais e perceptivas surgem necessidades de analisar temas e objetos de forma sistêmica e alternativa. O artigo propõe, com o olhar pautado em questões da qualidade do espaço construído de parques lineares, a elaboração de um método de análise da qualidade de projeto e da percepção dos usuários desses projetos após a implantação dos parques. Ghel enfatiza que a qualidade dos espaços construídos ao nível dos olhos, ou seja, na escala humana, pode ser decisiva na interpretação da qualidade de vida dos usuários e é através disso que consiste na discussão. Além de Gehl, outros autores embasaram o estudo apresentado, inclusive alguns que estabelecem reflexões sobre o ensino paisagismo, que servirão de base para a elaboração do método apresentado. O estudo consiste em elencar parâmetros que sejam significativos para o estudo do paisagismo, com foco no sistema de espaços livres da cidade, a fim de se tornar uma ferramenta para uma etapa do estudo de uma dissertação de mestrado.
\end{abstract}

Palavras-chave: Qualidade do espaço construído; parques lineares; percepção dos usuários; qualidade de projeto de parques lineares.

\begin{abstract}
Faced with a scenario investigated by visual and perceptual questions, the need arises to analyze themes and objects in a systemic and alternative way. The article proposes, with a view based on issues of the quality of the space constructed of linear parks, the elaboration of a method of analysis of the quality of the project and the perception of the users of these projects after the implementation of the parks. Ghel emphasizes that the quality of the spaces constructed at the level of the eyes, that is, in the human scale, can be decisive in the interpretation of the quality of life of the users and it is through this that it consists in the discussion. In addition to Gehl, other authors supported the study presented, including some reflections on landscaping teaching, which will serve as a basis for the elaboration of such a method. The study consists of listing parameters that are significant for the study of landscaping, focusing on the free space system of the city, in order to become a tool for a study stage of a master's thesis.
\end{abstract}

Keywords: Project quality; linear parks; perception of users; design quality of linear parks.

\section{INTRODUÇÃO}

Nas últimas cinco ou seis décadas, o mundo tem assistido ao desenrolar de uma primazia da visão sobre os outros sentidos e sensações. A maior parte da cultura produzida e consumida no mundo inteiro é, em vários aspectos, visual: a literatura e a leitura, a pintura, a escultura, o teatro, o cinema. Até mesmo as capas de discos e livros recorrem à visualidade. Em diversas áreas das ciências humanas e sociais, a visão e a percepção se tornaram categorias importantes para analisar diversos temas e objetos.

Talvez não por coincidência, na segunda metade do século passado alguns arquitetos voltaram sua atenção para a percepção e a sensibilidade do indivíduo, de uma forma geral, como Henri Lefebvre, Jane Jacobs e outros.

GODOY, L. A qualidade do espaço construído e a percepção em parques lineares. In: SIMPÓSIO BRASILEIRO DE QUALIDADE DO PROJETO NO AMBIENTE CONSTRUÍDO, 6., 2019, Uberlândia. Anais... Uberlândia: PPGAU/FAUeD/UFU, 2019. p. 388-396. DOI https://doi.org/10.14393/sbqp19037. 
Desde então tais temas tem sido pauta de reflexões que procuram sistematizar formas alternativas de conceber o espaço urbano.

É exatamente nessa esteira que Jan Gehl define o olho humano como a "escala mais importante para o planejamento urbano" (GEHL, 2010, p. 118). Gehl não descarta, no nível da menor escala, outras necessidades e sentidos, mas já em seu estudo sobre "O uso do espaço ao ar livre pelas pessoas em cidades e bairros residenciais" de Copenhague (1966), o estudioso já observava uma estruturação do sistema urbano segundo elementos sensoriais, conforme fica evidente na nota 31 do capítulo 5 de A vida na cidade: como estudar (GEHL e SVARRE, 2018, p. 166) - a indicação da inspiração nas teorias comportamentais de Robert Sommer e a própria parceria nos estudos com sua esposa que é psicóloga são boas evidências para entender o caminho que o pesquisador percorreu.

Como resultado disso, Gehl desenvolveu ao longo dos anos uma "Lista para avaliar a qualidade dos espaços públicos" (GEHL, 2018, p. 106) . Essa lista foi se modificando e sendo adaptada por ele ao longo dos últimos 40 anos: sua primeira versão foi publicada somente em 2006 em New City Life, e sua versão mais recente publicada em livro está presente em Cities for People, de 2010 (GEHL e SVARRE, p. 166).

Uma vez determinado que existe essa primazia do olhar enquanto escala do planejamento urbano e, então, da qualidade dos espaços públicos, é interessante procurar entender em que termos Gehl está definindo essa "qualidade": "[...] a qualidade da moradia e do espaço ao nível dos olhos pode ser [...] decisiva para a qualidade de vida, apesar das deficiências de outras áreas de planejamento" (GEHL, 2010, p. 118).

Quer dizer que a qualidade de vida é reflexo da qualidade da moradia e do espaço. Em todas as versões e publicações em que Gehl se debruça sobre o assunto, a ênfase recai nos aspectos funcionais e práticos oferecidos pelos espaços urbanos. Basta notar que, de seus doze critérios, os primordiais são de seguridade: proteção contra tráfego e acidentes; contra crimes e violência; contra climas desagradáveis; contra experiências sensoriais desagradáveis. Esse último, vale ressaltar, somente apresenta um aspecto visual, que seria desenvolvimento de cegueira. Assim, no rol de elementos funcionais não consta qualquer desconforto visual estético. Dos aspectos práticos, os que apontam mais detalhadamente as capacidades sensoriais a serem exploradas, remetem à "Possibilidade de ver" literal e estritamente. É somente no último critério, "Desfrutar experiências sensoriais positivas" que coube o item "qualidades estéticas". Fica assim claro de que visão Gehl está falando, e de que modo também a visão como escala funciona para o estudioso. O aspecto estético é fator de qualidade, mas é necessário que antes os aspectos funcionais e práticos do espaço tenham sido bem estruturados (GEHL e SVARRE, 2018, p. 106-107).

A proposta de Gehl se desenvolve assim a partir de elementos bem organizados e estruturados. É certo que, segundo o próprio nome dessa proposta, "Lista [de critérios] para avaliar a qualidade dos Espaços Públicos" (GEHL E SVARRE, 2018, p. 106, grifo nosso), a qual ele chamou de ferramenta em Cidades para pessoas - ele, na verdade, insere a lista dos critérios na seção "Caixa de Ferramentas" do livro (GEHL, 2010, p. 238) - a intenção é estabelecer parâmetros universais. 
Mais recentemente, entretanto, uma leva de estudos interdisciplinares tem posto em evidência o sistema cognitivo-participativo dos indivíduos, de modo que se altera, ao menos em teoria, o lugar do indivíduo em relação à escala espacial. Nos estudos sobre arquitetura, Florencio Zoido Naranjo apontou a relação entre a ordenação do espaço público e sua função democrática através da participação cidadã (NARANJO, 2002). Embora Naranjo recorra à diversos conceitos políticos e sociológicos, o autor demonstra mais claramente que esse sistema cognitivo-participativo reflete um elemento perceptivo: a construção de um aparato social e cultural responsável por ajudar a conceber os espaços urbanos (NARANJO, 2002).

De maneira semelhante, já no fim dos anos 1960, Kevin Lynch apontava a construção e ordenação dos espaços como resultantes da percepção e da atuação dos sujeitos na cidade (LYNCH, 1960).

Pensar todos esses elementos, entre a qualidade medida a partir da escala humana - mais especificamente a partir do olho humano - e a concepção e estruturação espacial através da percepção, pode ser necessário para compreender o espaço urbano na contemporaneidade, especialmente os espaços urbanos da contemporaneidade. É nesse aspecto que devem ser concebidos os parques lineares: espaços urbanos contemporâneos. Eugênio de Queiroga aponta que "a maioria dos projetos [de parques] concebidos na primeira década do século XXI já se mostra efetivamente mais sensivel ao papel ambiental [...] indo além dos programas convencionais ligados ao lazer e à prática de atividades físicas" (QUEIROGA, 2012, p. 99). E ainda mais que a sensibilidade ao papel ambiental, os planejamentos de parques contemporâneos têm aceitado também um papel social e histórico que levam à contribuição para construção de referências e identidade dos seus usuários.

É conveniente, nessa altura, apontar que a pesquisa da qual este texto resulta, procura justamente entender a qualidade do espaço construído de parques lineares e a percepção de seus respectivos usuários. Ou seja, incide sobre a proposta de Gehl, mas também visa entender a dimensão da percepção conforme sugerida por Lynch e Naranjo. Além disso, deve também compreender seu objeto, o parque, enquanto um produto de um momento histórico e social específico, conforme Queiroga esclareceu. Dessa maneira, o objetivo desse texto é justamente explorar estas questões de modo que elas possam ajudar a elaborar uma forma sistemática de estudar a qualidade do espaço construído de parques e a percepção dos indivíduos em relação a esse espaço construído em específico.

\section{FUNDAMENTAÇÃO}

Segundo Magnoli (apud QUEIROGA, 2012, pp. 73-74) os espaços livres são objetos do paisagismo, define espaços livres como livres de edificações, ou livre de urbanização. Tais como ruas, praças, parques, quintais, recuos laterais, pátios descobertos, terrenos baldios, praias, lagoas, rios, campos, florestas, áreas cultivadas, enfim, todos os espaços abertos não abrigados por coberturas edificadas. Segundo Queiroga (2012) compreende-se como sistema de espaços livres urbanos os elementos e as relações que organizam e estruturam todo o conjunto de espaços livres que um determinado recorte 
urbano independente de sua dimensão, de sua localização, qualificação estética, funcional e propriedade, sejam públicas ou privadas.

O parque é um elemento constituinte do sistema de espaços livres e desempenha um papel fundamental para a dinâmica da vida na cidade. São opções de lazer, interação social, contemplação e descanso. Atualmente o parque tem assumido diferentes configurações e distintos significados, como estratégia de conservação ambiental das cidades e como elementos de dinamização da economia urbana.

Os parques lineares se apresentam como um elemento público muito comum nas cidades brasileiras, eles surgiram como propostas de conexão de áreas de preservação permanente e a cidade, com o intuito de "costurar" a malha urbana com os espaços livres da cidade. As legislações na contemporaneidade têm exigido espaços ambientalmente qualificados e considerando então, que o sistema de espaços públicos livres de edificações constitui um importante princípio organizador da cidade e do território, os parques lineares surgiram como proposta de adequar conceitos de sustentabilidade nas cidades (BENFFATTI E SILVA, 2013).

Visto que, praças, parques, jardins e similares produzem a estrutura principal do sistema de espaços livres e públicos das cidades brasileiras é interessante analisar diante do que se tem enquanto produto desse sistema. Vale perceber que a maioria dos projetos concebidos na primeira década do século XXI apresentam um programa de necessidades que vão além dos convencionas ligados ao lazer e às atividades físicas.

Nota-se uma valoração de matas remanescentes e de cursos d'água para a conservação e uso público nos espaços urbanos. Assim, então, se define os parques lineares. Situados junto a APPs, foram e são fundamentais para a criação de corredores verdes que incentivam o convívio e o lazer, que estabelecem conexões ecológicas, que auxiliam na drenagem urbana e que funcionam como apoio para implantação de estruturas de mobilidade de baixo impacto ambiental.

Diante desses aspectos é claro o papel do parque linear inserido no conceito de urbanidade. Os sistemas de espaços livres, caracterizados pelos espaços não construídos, incluindo as áreas verdes, têm grande importância para a melhoria da qualidade de vida urbana. Para Tardin (2008), os espaços livres são peças fundamentais na ocupação e estruturação do território e devem ser considerados a partir dos seguintes pontos de vista: do urbano (importante elemento na definição do uso e ocupação do solo, bem como são áreas que possibilitam a criação de articulação espacial entre as partes do território); do sócio-cultural (como áreas que possibilitam o encontro, o lazer, o descanso, espaço de construção da cidadania); do perceptivo (lugar de criação da identidade visual que favorece a apropriação do espaço e transformação do mesmo em lugar); do biofísico (lugar dos fluxos bióticos, dos elementos abióticos e das dinâmicas e processos naturais, fundamentais para a manutenção e o equilíbrio ambiental do território) (TARDIN, 2008, pp. 144-157).

É possível buscar objetividade na interpretação de projetos através de parâmetros de análise. Tais parâmetros indicam a possibilidade de mensurar a qualidade do espaço construído através de uma análise qualitativa. $\bigcirc$ artigo tem como discussão, através de uma revisão bibliográfica, definir parâmetros 
de análise que serão conceituados e aplicados para a elaboração de uma metodologia de estudo de parques lineares.

\section{METODOLOGIA}

O estudo foi elaborado a partir de parâmetros que foram elencados a partir de uma revisão de estudos. A base da revisão foram conceitos que serviram como referência para o estudo da paisagem. Através dos parâmetros elencados se propõe uma metodologia de compreensão do espaço construído dos parques lineares.

É pertinente deixar claro que alguns dos estudos que serviram de referência (como Feghali e Tardin) se baseiam em uma transposição da análise da paisagem até a etapa de projeto, afinal se tratam de metodologias pedagógicas do ensino de paisagismo. Difere da problematização tratada no artigo, visto que este se enquadra em analisar o espaço construído, o projeto paisagístico e arquitetônico de parques lineares implantados. E tem como objetivo, através dos parâmetros elencados, fomentar a discussão acerca dos modelos que estão sendo produzidos atualmente, ou seja, uma análise pósocupação.

Mesmo com essa diferença, a inspiração advinda de metodologias pedagógicas se tornou um instrumento válido na abordagem. Segundo Feghali, esses conceitos possibilitam a integração em diferentes dimensões de análise do espaço: morfológico, comportamental e sensorial e são relevantes para a apreensão dos espaços livres públicos pois permitem uma análise não só interpretativa, mas também valorativa dos contextos de intervenção (FEGHALI, 2007, pp. 11). Ou seja, além de elementos físicos, os parâmetros escolhidos consideram elementos de valores na elaboração de uma crítica da paisagem do espaço construído.

Os parâmetros escolhidos foram elencados diante uma seleção de alguns autores. Segundo Aguiar, Kevin Lynch contribuiu na tentativa dos elementos da urbanidade. Lynch propõe e exercita um "modo prazeroso" de olhar a cidade como um conjunto de sequências espaciais onde, nas palavras do autor, "os elementos móveis de uma cidade e, em especial, as pessoas e suas atividades, são tão importantes quanto as partes físicas estacionárias" (AGUIAR, 2006, pp.66). De sua estrutura de análise foram selecionados dois conceitos que embasaram dois parâmetros de análise, são eles:

Vias (paths): São os canais ao longo dos quais o observador se move, usual, ocasional ou potencialmente. Podem ser ruas, passeios, linhas de trânsito, canais, trilhos de ferro. Para muitos, estes são os elementos predominantes na sua imagem. As pessoas observam a cidade à medida que nela se deslocam e os outros elementos organizam-se e relacionam-se ao longo destas vias.

Limites (edges): são os elementos lineares não usados nem considerados pelos habitantes como vias. São as fronteiras entre duas partes, interrupções lineares na continuidade, costas marítimas ou fluviais, cortes no trilho de ferro, paredes, locais de desenvolvimento. Funcionam, no fundo, mais como referências secundárias do que como alavancas coordenantes; tais limites, podem ser barreiras mais ou menos penetráveis que mantêm uma região isolada das outras, podem ser "costuras", linhas ao longo das quais regiões se relacionam e se encontram. Estes elementos limites, embora não tão importantes como as 
vias, são, para muitos, uma relevante característica organizadora, particularmente quando se trata de manter unidas áreas diversas, como acontece no delinear de uma cidade por uma parede ou por água. Fronteiras; encontram. São espécies de fronteiras entre dois lugares que se confluem ou que são adjacentes.

Para Tardín, um conceito muito importante se trata de uma busca por definições que identifiquem características mais genuínas dos elementos físicos que compõem os espaços e que podem ser percebidos como parte da identidade visual da área (TARDIN, 2008, pp. 148-157). Ela define, então, como atributos perceptivos em seu estudo, são eles:

Os elementos cênicos: São considerados como elementos cênicos os componentes naturais dos espaços livres com uma qualidade visual intrínseca. Eles se caracterizam como componentes naturais dos espaços livres com maior atrativo visual, o que Ihes confere uma qualidade única. A importância desses elementos se reflete no caráter que imprimem à composição de determinada paisagem, sendo parte significativa de sua identidade visual, como, por exemplo, as singularidades do relevo, da vegetação e da hidrografia.

As áreas de emergência visual: Referem-se aos elementos singulares que compõem os espaços livres, especificamente o relevo e a hidrografia, e que podem ser percebidos desde os percursos pelas vias. Se apresentam como enquadramentos singulares que marcam as sequências dos percursos como elementos diferenciados, que favorecem mudanças no ritmo frequente da paisagem percebida. Podem funcionar como elementos de tensão que despertam o interesse pelo entorno visual, estabelecendo a relação entre o comum e o diferenciado.

Os fundos cênicos: correspondem às visadas mais amplas da paisagem permitidas pelos espaços livres, que podem ser: vistas parciais, que abarcam uma parte mais limitada da paisagem, e vistas panorâmicas, que podem ser contempladas a partir de pontos com cota mais elevada e oferecem visadas mais gerais.

Os marcos históricos: são privilegiados os espaços livres de interesse históricocultural que, geralmente, permaneceram como remanescentes da ocupação urbana. Estes espaços costumam ser testemunhas da história e representativos de valores tradicionais, que requerem ser identificados e avaliados, portanto deveriam ter a ocupação urbana limitada (apud TARDIN, 2008, pp. 73-74).

Vale ressaltar que todos esses parâmetros no momento da eleição possuem um alto grau de subjetividade e está sujeita a distintas considerações sobre seu valor.

Para Feghali (2007, pp.12) a criação dos conceitos como metodologia pedagógica possibilita a valorização dos aspectos de uma situação a ser analisada. E os parâmetros que serão utilizados como referência são:

a) Significação: mede a intensidade simbólica dos diferentes componentes paisagísticos;

b) Continuidade: sugere a atribuição de uma identidade (persistência de limite/superfície);

c) Viscosidade: resistência ao movimento, graus de aderência ao espaço; 
Para Ghel a lista de critérios de qualidade foi desenvolvida com base em conhecimentos fundamentais sobre sentidos e necessidades humanas e sobre o que faz as pessoas se sentirem confortáveis e permanecerem no espaço público (GEHL e SVARRE, p. 106). Os parâmetros, então, considerados nessa análise foram:

a) Proteção contra o tráfego: Proteção contra tráfego e acidentes (segurança para os pedestres e ausência de motivos para temer o tráfego);

b) Segurança: Proteção contra crimes e violência (espaços públicos cheios de vida, circulação de pessoas, boa iluminação);

c) Experiências sensoriais: Proteção de experiências sensoriais desagradáveis (vento, chuva, sol, barulho, poeira, etc.);

d) Espaços para caminhar: Fachadas interessantes, ausência de obstáculos, superfícies regulares e acessibilidade;

e) Espaços de permanência: locais agradáveis e confortáveis para permanecer por algum tempo, com fachadas interessantes para contemplar);

f) Ter onde se sentar: Mobiliário urbano confortável para sentar e descansar, voltado para atrações, vistas e passagem de pessoas;

g) Possibilidade de observar: Possibilidade de paisagens para observar (vistas interessantes, paisagens que não estejam escondidas);

h) Oportunidade de conversar: Condições que proporcionem baixos níveis de ruído e mobiliário urbano que convide à interação entre as pessoas;

i) Locais para se exercitar: Locais para exercitar/divertir (espaços e equipamento público para praticar esportes, entretenimento e atividades na rua, de dia, de noite, na seca e na chuva);

j) Escala humana: Paisagem projetada para serem vistos a partir da altura das pessoas, não do alto;

k) Possibilidade de aproveitar o clima: Locais para aproveitar cada estação, de acordo com o clima e a topografia da cidade. Exemplos: piscinas públicas para aproveitar o calor, grama para se sentar, com árvores que façam sombra para amenizar o sol, etc.;

I) Boa experiência sensorial: Projeto paisagístico com diferentes espécies, arborização, mobiliário urbano, presença de água.

E a vitalidade, muito analisada por Ghel, então definida como um espaço convidativo. Caracteriza os espaços como vivos quando transpassam sinais amistosos e acolhedores que promovem integração social. Esclarece este conceito como relativo sendo que a vitalidade nas cidades não se limita à quantidade de pessoas e sim a sensação que o espaço transmite, se ela convida ou afasta as pessoas, se as atividades sociais e de lazer estão combinadas ou fragmentadas. (GHEL, 2013, pp.75).

\section{CONSIDERAÇÕES FINAIS}

A partir da elaboração dos parâmetros de qualidade do espaço construído, é possível compreender uma estrutura de avaliação da percepção dos usuários 
sobre os parques lineares. Assim, a aplicação de tais parâmetros no contexto de parques analisados, através dessas visões permitirão uma comparação qualitativa que evidencie os usos e as apropriações dos espaços livres e parques lineares.

O que se apresenta enquanto resultado da pesquisa até o momento se trata de uma revisão bibliográfica que resulta na eleição dos parâmetros da análise da qualidade de projeto e percepção dos usuários, que serão determinantes para uma pesquisa maior, ou seja, a aplicação está contida em uma etapa de uma dissertação de mestrado que tem como objetivo levantar e discutir questões frente aos modelos de parques lineares que vem sendo produzidos e implantados nas cidades.

\section{REFERÊNCIAS}

AGUIAR, Douglas. .In: HOLANDA, Frederico de; ANDRADE, Luciana; KRAFTA, Romulo; TRIGUEIRO, Marcele; RHEINGANTZ, Paulo Afonso; FIGUEIREDO, Lucas; NETTO, Vinicius M. (Orgs.). Urbanidades. Rio de Janeiro, RJ, FAPERJ, Folio Digital, 2012

COCOZZA, Glauco de Paula; OLIVEIRA, Lucas Martins de; LIBERA, Izabela llka Medeiros Dalla. O sistema de espaços livres e a constituição da forma urbana na cidade de Uberlândia, MG. In: COLÓQUIO QUAPÁ-SEL, 6, 2011, São Paulo. $6^{\circ}$ Colóquio QUAPÁ-SEL. São Paulo, 2011

CULLEN, G. Paisagem Urbana. São Paulo: Martins Fontes, 2006.

FEGHALI, Maria Elisa; LASSANCE, Guillherme. Da análise às intenções do projeto: conceitos para o processo de concepção da paisagem. In: Paisagem e Ambiente, São Paulo, n. 23, p. 10-19, june 2007. ISSN 2359-5361. Disponível em: https://www.revistas.usp.br/paam/article/view/86864. No dia 26/11/17

GEHL, J. Cidades para pessoas. São Paulo: Perspectiva, 2013.

GEHL, J. Life between buildings: using public space. Washington: Island Press, 2011.

GEHL, J.; SVARRE, B. How study public life. Washington: Island Press, 2013.

LYNCH, K. A imagem da cidade. São Paulo: Marins Fontes, 1997.

NARANJO, Florencio Zoido. "El paisaje y su utilidade para la ordenación del territorio". In: Consejería de Obras Públicas y Trasnportes. Paysaje y ordenación del territorio. Andaluzia: Junta de Andalúcia/Consejería de Obras Públicas y Trasnportes, 2002.

QUEIROGA, Eugênio Fernandes. Dimensões públicas do espaço contemporâneo: resistências e transformações de territórios, paisagens e lugares urbanos brasileiros. São Paulo: FAUUSP, 2012. 284 F. Tese (Doutorado em Livre Docência) - Programa de Pós-Graduação em Arquitetura e Urbanismo, Faculdade de Arquitetura e Urbanismo, Universidade Federal de São Paulo, São Paulo, 2012.

REIS, Antônio Tarcísio da Luz; LAY, Maria Cristina Dias. Avaliação da qualidade de projetos - uma abordagem perceptiva e cognitiva. In: Ambiente construído. Porto Alegre, v. 6, n. 3, p. 21-34, jul./set. 2006. Disponível em: https://www.lume.ufrgs.br/handle/10183/55493. Acesso em 15/11/2018. 
SERPA, Angelo. Milton Santos e a Paisagem: Parâmetros para a Construção de uma Crítica da Paisagem Contemporânea. In: Paisagem e Ambiente, São Paulo, n. 27, p. 131-138, june 2010. ISSN 2359-5361. Disponível em:

http://www.revistas.usp.br/paam/article/view/77376. Acesso em 26/11/17.

TÂNGARI, Vera; SCHLEE, Mônica; NUNES, Maria; REGO, Andrea; RHEINGANTZ, Paulo; DIAS, Maria. Sistema de espaços livres nas cidades brasileiras - um debate conceitual. In: Paisagem Ambiente: ensaios - n. 26 - São Paulo - p. 225 $247-2009$.

TARDIN, R. Espaços livres: sistema e projeto territorial. Rio de Janeiro: 7Letra, 2008. 